\title{
Comparative Study of Evolutionary Algorithms for the Optimum Design Of Thin Broadband Multilayer Microwave Absorber for Oblique Incidence
}

\author{
JyotirmayTewary, G.K.Mahantiand KajlaBasu \\ ${ }^{1}$ Department of Electronics and Communication Engineering, \\ Bengal College of Engineering \& Technology, Durgapur, India \\ ${ }^{2}$ Department of Electronics and Communication Engineering, \\ National Institute of Technology, Durgapur, India \\ ${ }^{3}$ Department of Mathematics, \\ National Institute of Technology, Durgapur, India
}

\begin{abstract}
With the increasing levels of Electromagnetic pollution almost exponentially in this modern age of Electronics reported and highlighted by numerous studies carried out by scientists from all over the world, inspire engineers to concentrate their research for the optimum design of multilayer microwave absorber considering various parameters which are inherently conflicting in nature. In this paper we mainly focus on the comparative study of different Evolutionary algorithms for the optimum design of thin broadband (2$20 \mathrm{GHz})$ multilayer microwave absorber for oblique incidence $\left(30^{\circ}\right)$ considering arbitrary polarization of the electromagnetic waves. Different models are presented and synthesized using various Evolutionary algorithm namely Firefly algorithm (FA), Particle swarm optimization (PSO), Artificial bee colony optimization $(A B C)$ and the best simulated results are tabulated and compared with each others.
\end{abstract}

\section{KEYWORDS}

Multilayer microwave absorber, oblique incidence, TE polarization, TM polarization, Particle swarm optimization (PSO), Firefly algorithm (FA), Artificial bee colony optimization (ABC).

\section{INTRODUCTION}

In today's world as electromagnetic pollution levels are reaching an alarming proportions increasing almost exponentially microwave absorber find its wide range of applications in almost all military and civil electronics systems for their properties to attenuate energy in an electromagnetic wave and can capable to eliminate stray or unwanted radiation that may interfere with the system operation and can degrade its performance .Earlier single layer absorber have been studied for many years but they find their limitations of narrow frequency band and thick structure. Hence recently more and more attention has been given for the optimum design of multilayer microwave absorber such that they must have minimum reflection coefficient of the electromagnetic wave in a specific band of frequencies for any angle of incidence and arbitrary polarization of the electromagnetic waves at the same time the absorber should be thin and light 
weight as well which makes the above problem a multi objective optimization problem to find out a proper trade-offs between various parameters of the microwave absorber such as choice of materials from a predefined database of existing materials, frequency range, incidence angle , number of layers, type of polarization, permittivity, permeability. However it has been solved successfully in many papers by applying various evolutionary optimization algorithm such as Genetic algorithm(GA)[1-3,6],Central force optimization (CFO)[7], Differential evolution(DE)[8],particle swarm optimization(PSO)[4-5,13-21],Firefly algorithm(FA)[22-24] and many more. In this paper we mainly focus on the comparative study of three most popular evolutionary optimization algorithms namely Firefly algorithm(FA),Particle swarm optimization(PSO), and Artificial bee colony optimization(ABC)[25,26] algorithm for the optimum design of multilayer microwave absorber for oblique incidence $\left(30^{\circ}\right)$ in the wide frequency band $(2-20 \mathrm{GHz})$ considering arbitrary polarization of the electromagnetic waves. The total thickness of the absorber is also included with the reflection coefficient while formulating the cost function to make our design more convenient for practical use. In this paper our study is organized as follows: Section 2 gives the brief overview of the physical model of multilayer microwave absorber. Section 3 describes the cost function or fitness function to be optimized using evolutionary optimization algorithms. A brief overview of particle swarm optimization (PSO), Firefly algorithm (FA), Artificial bee colony optimization (ABC) to solve the above mentioned problem is described in section 4. Simulation results and subsequent discussions are described in section 5, while the concluding arguments are explained in section 6.

\section{GENERALIZED MODEL OF MULTILAYER MICROWAVE ABSORBER}

The generalized structure of multilayer microwave absorber illustrated in Fig.1 is formed by cascading $\mathrm{N}$ number of layers of different materials with frequency dependent permittivity and permeability available from specific predefined material database and is backed by perfect electric conductor (PEC) which acts as an ideal reflection object and consider as the last layer (layer number $\mathrm{N}+1$ ) of the multilayer structure of the microwave absorber. The electromagnetic wave travel through the free space(air) which is consider as layer number 0 and incident obliquely at the first surface of the multilayer structure making an incident angle $\theta$ with the $\mathrm{Z}$ axis (normal) at the point of incidence. When this electromagnetic wave is travelled through the multilayer structure certain parts of its energy is being absorbed in each layer, and is reflected back by the last layer (layer number $\mathrm{N}+1$ ) formed by perfect electric conductor(PEC). Now from the concept of transmission line theory [9] the generalized reflection coefficient between any two layers of the multilayer structure can be determined using the following algorithm:

$$
R_{i, i+1}=\frac{\rho_{i, i+1}+R_{i+1, i+2} \exp \left(-2 j k_{i+1} d_{i+1}\right)}{1+\rho_{i, i+1} R_{i+1, i+2} \exp \left(-2 j k_{i+1} d_{i+1}\right)}
$$

Where,

For TM (parallel) polarization:

$$
\rho_{i, i+1}=\frac{\varepsilon_{i+1} k_{i}-\varepsilon_{i} k_{i+1}}{\varepsilon_{i+1} k_{i}+\varepsilon_{i} k_{i+1}} i<N
$$


For TE (perpendicular) polarization:

$$
\rho_{i, i+1}=\frac{\mu_{i+1} k_{i}-\mu_{i} k_{i+1}}{\mu_{i+1} k_{i}+\mu_{i} k_{i+1}} i<N
$$

In the above equations,

$\varepsilon_{i}=$ frequency dependent complex permittivity of $\mathrm{i}^{\text {th }}$ layer.

$\mu_{i}=$ frequency dependent complex permeability of $\mathrm{i}^{\text {th }}$ layer.

$k_{i}=$ wave number of the $i^{\text {th }}$ layer and according to Snell's law it is related with the incident angle $\theta$ as follows:

$k_{i}=\omega \sqrt{\mu_{i} \varepsilon_{i}-\mu_{0} \varepsilon_{0} \sin ^{2}(\theta)}(4)$

In equation (4), $\omega$ represents the frequency of the incident wave whereas $\varepsilon_{0}$ and $\mu_{0}$ denote the permittivity and permeability of free space respectively, i.e.

$$
\begin{aligned}
\varepsilon_{0}=8.854 * 10^{-12} \frac{F}{m}(5) \\
\mu_{0}=4 \pi * 10^{-7} \frac{H}{m}(6)
\end{aligned}
$$

In this paper while designing the multilayer structure of the microwave absorber the misconception that for normal incidence both TM and TE polarization don't have the same magnitude of the reflection coefficient [8] and wrongfully set the reflection coefficient between the last layer of the multilayer structure and the $\operatorname{PEC}\left(R_{N, N+1}\right)$ to -1 for both TE and TM polarizations deals with the same problem in several papers $[10,11,12]$ has been traced out and it has been emphasized that it should be set to +1 for TM polarization where as it set to -1 for TE polarization of the electromagnetic wave otherwise it results in different values for the magnitude of the reflection coefficient for normal incidence but which is not the case actually. Taken this above concept under consideration the overall reflection coefficient of the multilayer microwave absorber is now computed recursively using the equations (1)-(6).

Incident wave $H(E)$
$E(H)$
$\theta \theta 0$
$\varepsilon_{1}, \mu_{1}$
$\varepsilon_{2}, \mu_{2}$

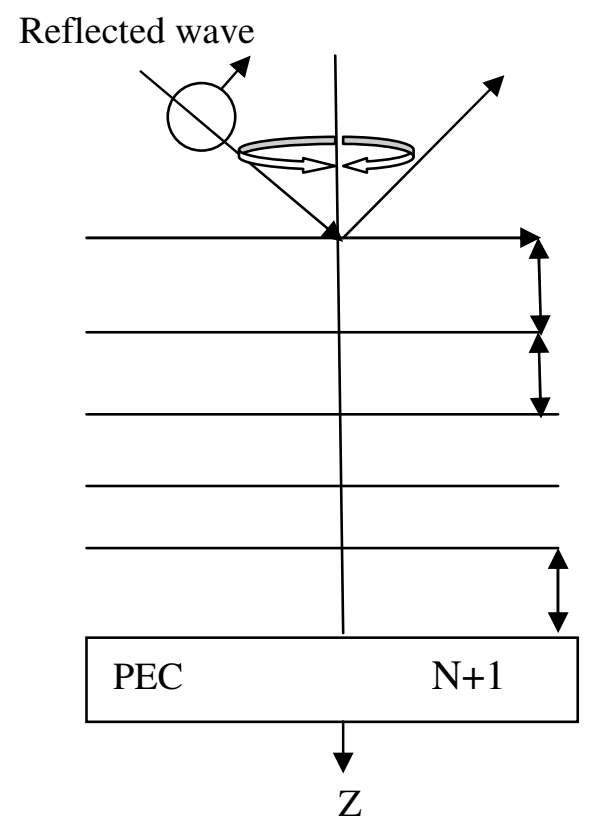

Fig 1.Generalized Physical Model of Multilayer Microwave Absorber. 


\section{PROBLEM FORMULATION}

The primary objective of our design is to obtain a multilayer structure of the microwave absorber which is formed by cascading of $\mathrm{N}$ different materials having frequency dependent permittivity and permeability choosing from predefined database of the existing materials that minimize the overall reflection coefficient of the microwave absorber for wide band of frequency $(2-20 \mathrm{GHz})$ and a particular incidence angle of $30^{\circ}$ considering both TE and TM polarizations of the electromagnetic wave. It is also required that the thickness of the multilayer structure of the absorber should be least practically possible therefore both these design considerations are incorporated in the form of following objective function for the purpose of optimization.

Minimum $\mathrm{F}=\mathrm{K}_{1} * 20 \log _{10}\left(\max \left(\left|\mathrm{R}_{01}\right|\right)\right)+\mathrm{K}_{2} \sum_{i=1}^{N} d_{\mathrm{i}}(7)$

Where the sum of all the individual layer thickness in meter is also optimized along with the weighted sum of overall maximum reflection coefficient of the multilayer microwave absorber $\mathrm{K}_{1}, \mathrm{~K}_{2}$ are weighting constants emphasizing each of the term associated with the fitness function and has been set to $K_{1}=1$ and $K_{2}=3000$ respectively for all the models studied in our design consideration optimized using three different evolutionary optimization algorithm namely particle swarm optimization(PSO), Firefly algorithm(FA), Artificial bee colony optimization( $\mathrm{ABC})$ in this paper.

\section{ALGORITHM OVERVIEWS AND PARAMETRIC SETUP}

\subsection{Overview of firefly algorithm (FA)}

FA is a Swarm based optimization algorithm and the concept was first developed by XinSheYang .The flashing characteristics of the fireflies is related with the objective function to be optimized by the algorithm and the concept was developed from the study of social behaviour of the fireflies that how they communicate with each other. In this algorithm the glowing fireflies is considered as the search agents and characterized by two parameters such as the location of the fireflies in the $d$-dimensional search space and the light intensity or brightness of the fireflies, asthe brightness or light intensity of the fireflies changes the fireflies also changes their location accordingly and the algorithm approaches towards its optimum solution. The algorithm can be summarized as per the flowchart given in fig2.

\subsection{Overview of Artificial bee colony optimization (ABC) algorithm}

$\mathrm{ABC}$ algorithm is also a swarm based optimization algorithm which was first introduced by Basturk and Karaboga. In ABC algorithm there are three groups of bees namely employed bees, onlookers and scouts where the searching ability of $\mathrm{ABC}$ algorithm lies on different behaviours of these three groups of bees whereas the positions of the food sources around a colony of artificial bees denoted the solutions of an optimization problem. The algorithm can be summarized as per the flowchart given in the fig3. 


\subsection{Overview of particle swarm optimization (PSO) algorithm}

The PSO algorithm is easy to implement and has been empirically shown to perform well on many optimization problems whose basic concept was first developed and introduced by Kennedy and Eberhart in 1995 which is based on the swarm behaviour of insects, animals herding, birds flocking and fish schooling where the search for the food is carried out by the swarm in a collaborative manner. In this concept the searching pattern of each swarm is adapted from its own as well as other member's experience. In PSO each members of the swarm also called particle represents the potential solution which is a point in the search space and the location of the food is the global optimum. The flying direction of each particle has been adjusted by its fitness value and a velocity corresponding to the best experiences of the swarm to search for the Global optimum in the D-dimensional search space. The algorithm can be summarized as per the flowchart given in the fig4.

Table 1. Parametric Setup ofthePSO, FA andABC Algorithms

\begin{tabular}{|c|c|c|c|c|c|}
\hline \multicolumn{2}{|c|}{ PSO } & \multicolumn{2}{|c|}{ FA } & \multicolumn{2}{|c|}{$\mathbf{A B C}$} \\
\hline Parameters & Values & Parameters & Values & Parameters & Values \\
\hline $\begin{array}{l}\text { Particle } \\
\text { number }\end{array}$ & 40 & $\begin{array}{l}\text { Number of } \\
\text { fireflies }\end{array}$ & 40 & $\begin{array}{l}\text { colony size } \\
\text { (NP) }\end{array}$ & 40 \\
\hline $\begin{array}{l}\text { Acceleration } \\
\text { constant } c_{1} \\
\text { Acceleration } \\
\text { constant } c_{2}\end{array}$ & $\begin{array}{l}1.4945 \\
1.4945\end{array}$ & $\beta_{0}$ & 0.20 & $\begin{array}{c}\text { limit for } \\
\text { abandonment }\end{array}$ & 5 \\
\hline $\begin{array}{c}\text { Inertia weight } \\
\text { w }\end{array}$ & $\begin{array}{c}\text { damp } \\
\text { linearly from } \\
0.9 \text { to } 0.2 \\
\text { with } \\
\text { iterations } \\
\end{array}$ & $\gamma$ & 1 & Food number & $\mathrm{NP} / 2$ \\
\hline $\begin{array}{l}\text { VR min } \\
\text { VR max }\end{array}$ & $\begin{array}{l}0 \\
1\end{array}$ & $\alpha$ & 0.9 & - & - \\
\hline $\begin{array}{c}\text { Search space } \\
\text { dimension }\end{array}$ & 10 & $\begin{array}{c}\text { Search space } \\
\text { dimension }\end{array}$ & 10 & $\begin{array}{c}\text { Search space } \\
\text { dimension }\end{array}$ & 10 \\
\hline Run no & 20 & Run no & 20 & Run no & 20 \\
\hline $\begin{array}{l}\text { Termination } \\
\text { condition }\end{array}$ & $\begin{array}{c}1000 \\
\text { iterations } \\
\max \end{array}$ & $\begin{array}{l}\text { Termination } \\
\text { condition }\end{array}$ & $\begin{array}{c}1000 \\
\text { iterations } \\
\max \end{array}$ & $\begin{array}{c}\text { Termination } \\
\text { condition }\end{array}$ & $\begin{array}{r}1000 \\
\text { Iterations } \\
\max \end{array}$ \\
\hline
\end{tabular}

Table 2. Predefined Database of Existing Materials [7, 8] 


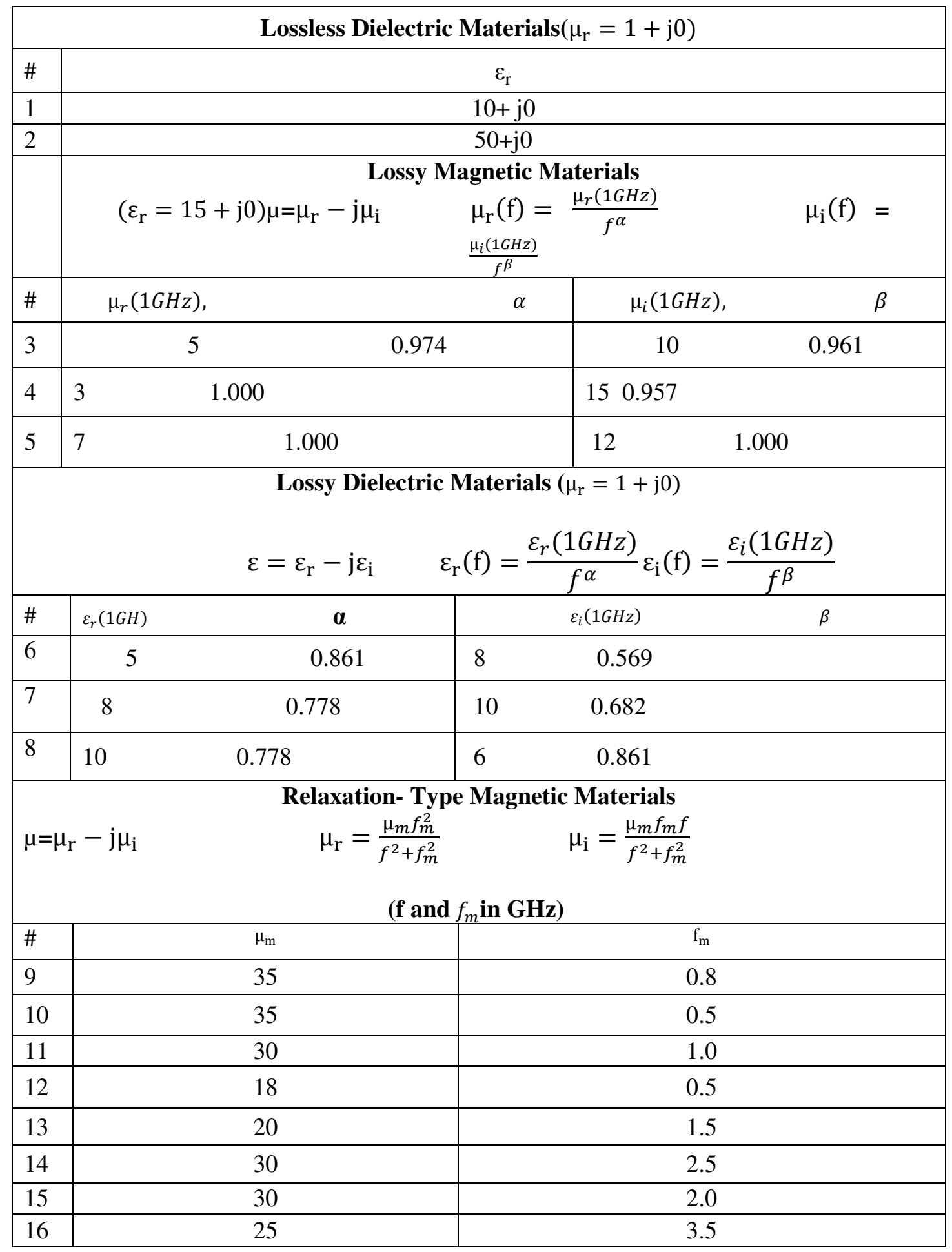


International Journal of Microwave Engineering (JMICRO) Vol.1, No.1, January 2016

Fig 2.

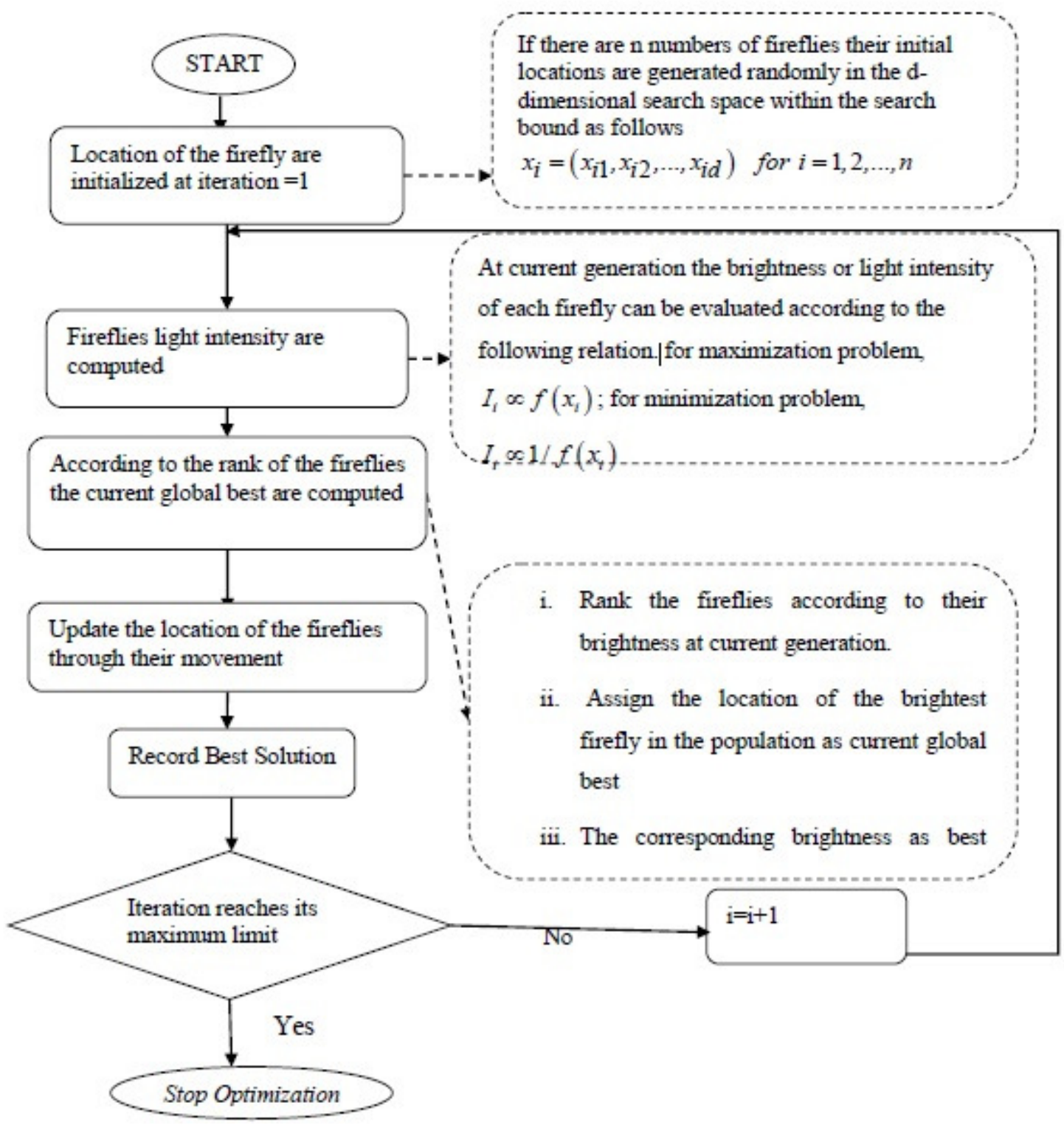

Fig 2. Flowchart Of FA 


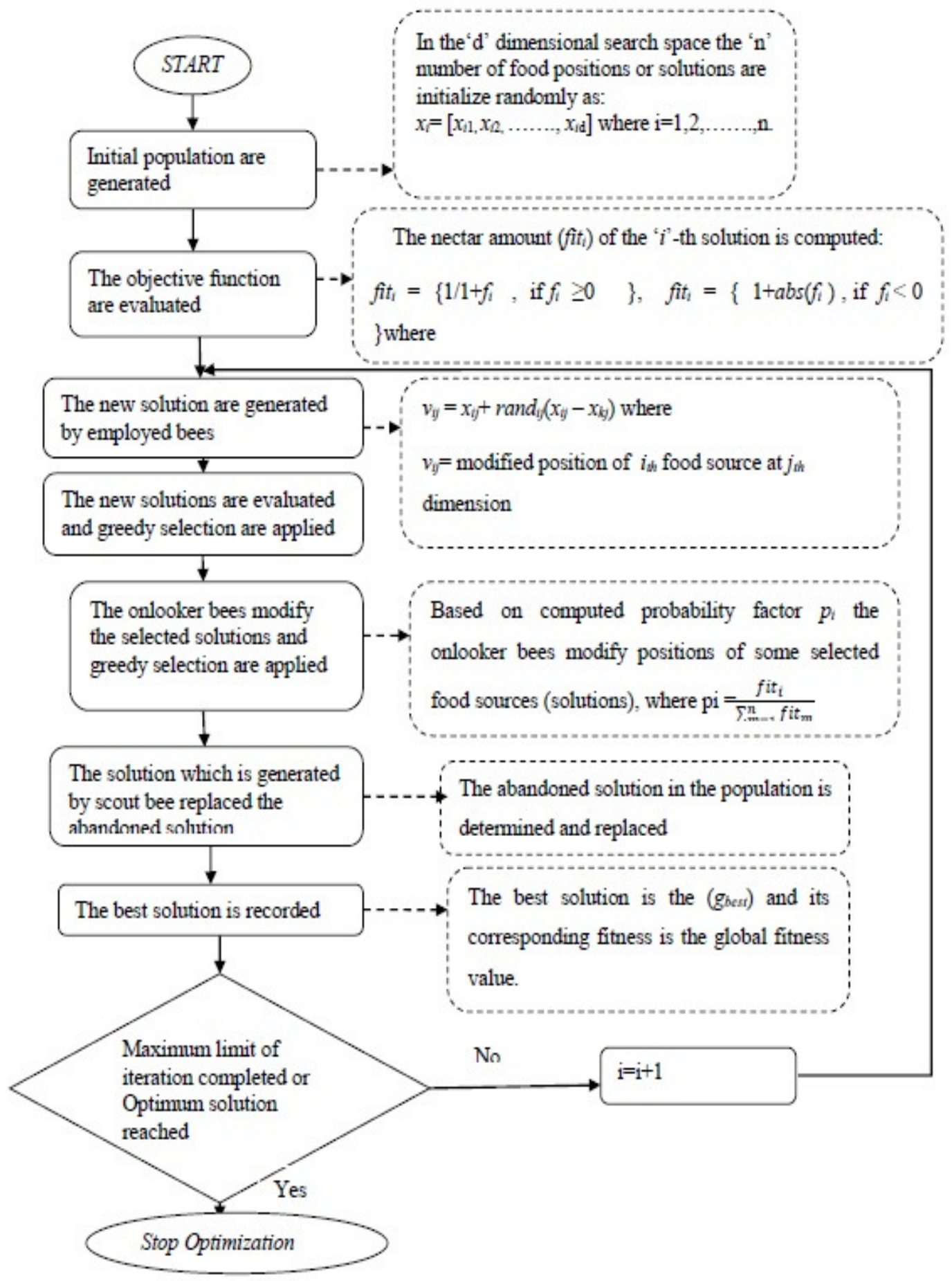

Fig3. Flowchart Of ABC Algorithm 


\section{RESULTS AND DISCUSSION}

The comparative study of different evolutionary algorithm such as particle swarm optimization (PSO), firefly algorithm (FA) and artificial bee colony optimization (ABC) are presented in this paper for the optimum design of 5 layer microwave absorber for oblique incidence $\left(30^{\circ}\right)$ considering TE and TM polarization of the electromagnetic wave and for wide range of frequency $(2-20 \mathrm{GHz})$ with a frequency increase of $0.1 \mathrm{GHz}$ at each step. 4 different models are presented optimized for overall reflection coefficient and total thickness of the absorber and only for overall reflection coefficient of the absorber without optimized the total thickness. Three different evolutionary algorithms are applied for optimization in each case and there parametric and statistical comparison is tabulated in table $3,4,5,6,7,8,9$ and 10 respectively for each model. It has been observed that for model1 (optimized for oblique incidence $\left(30^{\circ}\right)$, TM polarization considering overall reflection coefficient and total thickness of the absorber simultaneously) FA gives the better frequency response for optimizing the overall reflection coefficient of the absorber but PSO results in ultra-thin absorber among all algorithms. Similarly for model 2 (optimized for only overall reflection coefficient of the absorber considering oblique incidence $\left(30^{\circ}\right)$ and TM polarization) PSO becomes more effective regarding optimization of the overall reflection coefficient of the absorber but as per as thinner absorber design is concern $\mathrm{ABC}$ comes out to be the clear winner over all other situations. Model3 (optimized for overall reflection coefficient and total thickness of the absorber considering TE polarization of the electromagnetic wave and $30^{\circ}$ incidence angle) PSO results in much thinner absorber and moderate frequency response over desired frequency band. Similarly for model 4 (considering TE polarization and incidence angle of $30^{\circ}$ and optimized for only overall reflection coefficient of the absorber) it has been observed that PSO results in better frequency response over desired frequency band while $\mathrm{ABC}$ results in slightly thinner absorber design as compare to other algorithms.fig.5, 6, 7, 8 represents the frequency response for model1, 2, 3, 4 optimized using different evolutionary algorithm while the variation of mean gbest value with iterations for all the above designs are presented in fig.9,10,11 and 12 respectively. For simulation all the three algorithms are run for 20 independent trials and each time the maximum number of iterations is set to 1000 .

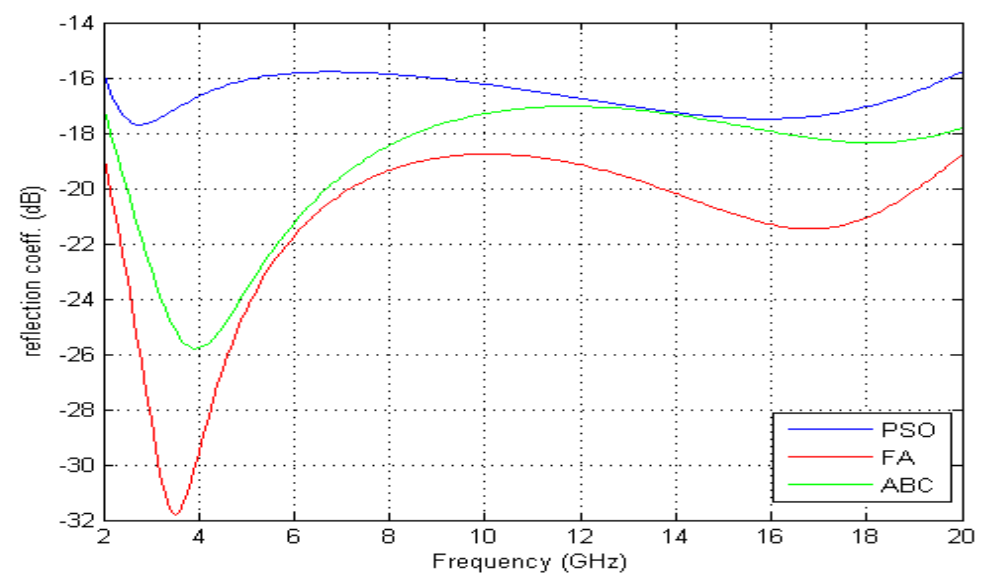

Figure 4. Reflection Coefficient Versus Frequency For Model1 
International Journal of Microwave Engineering (JMICRO) Vol.1, No.1, January 2016

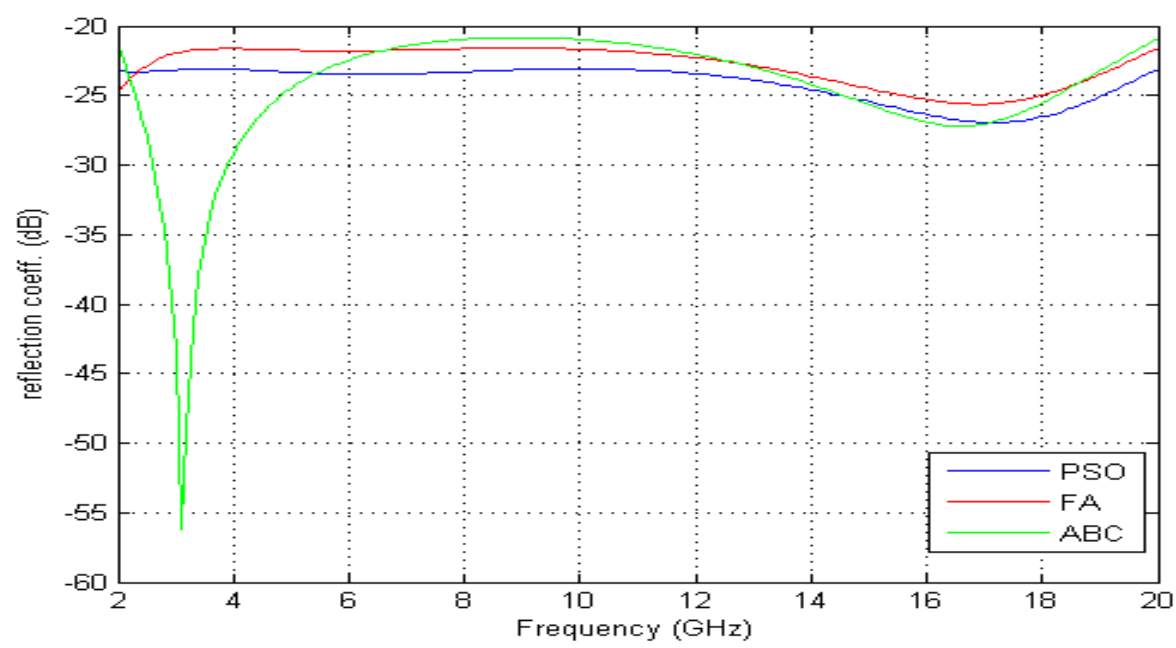

Figure 5. Reflection Coefficient Versus Frequency For Model2

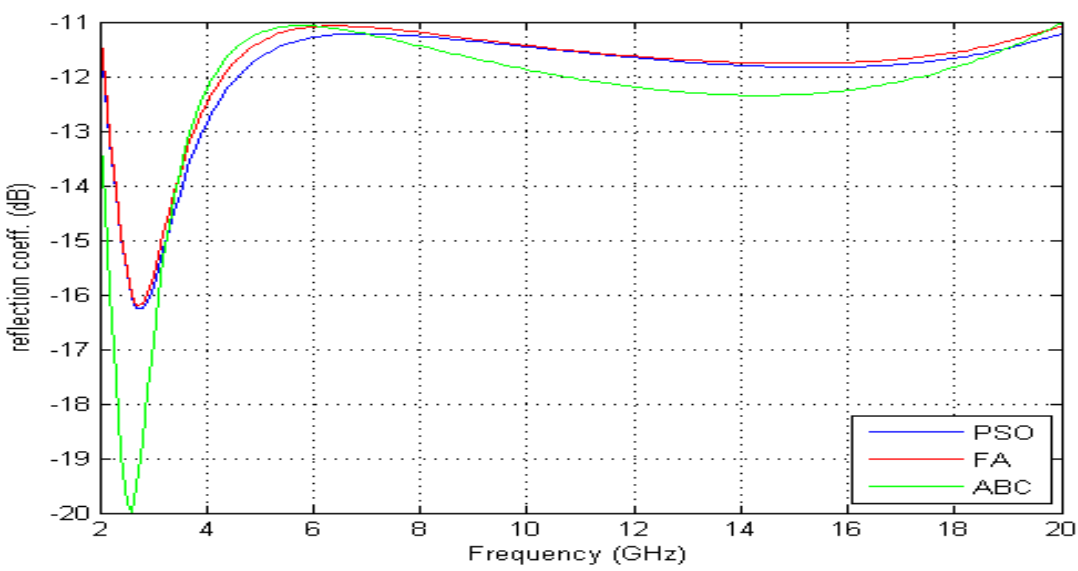

Figure 6.Reflection Coefficient Versus Frequency For Model3

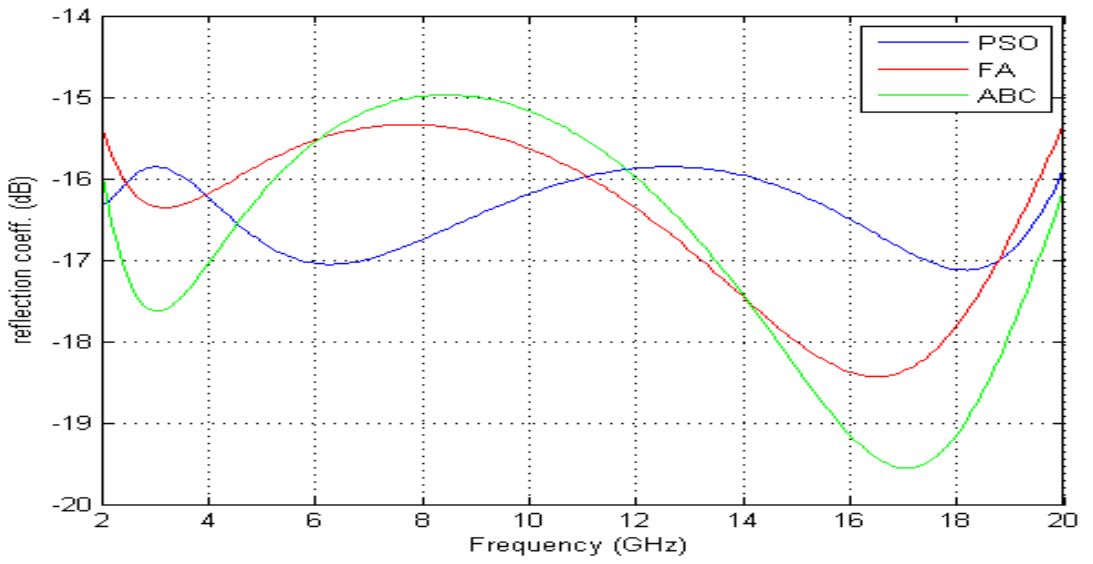

Figure 7. Reflection Coefficient versus Frequency for Model4 
International Journal of Microwave Engineering (JMICRO) Vol.1, No.1, January 2016

Table 3. Parameters for Microwave Absorber Design for Oblique Incidence $\left(30^{\circ}\right)$ TM Polarization

Optimized For Overall Reflection Coefficient and Total Thickness of the Absorber (Model1)

\begin{tabular}{|c|c|c|c|c|c|c|}
\hline \multirow[b]{2}{*}{ Layer } & \multicolumn{2}{|c|}{ PSO } & \multicolumn{2}{|c|}{ FA } & \multicolumn{2}{|c|}{$\mathrm{ABC}$} \\
\hline & $\begin{array}{c}\text { Material } \\
\text { No. }\end{array}$ & $\begin{array}{c}\text { Thickness } \\
\text { in } \mathbf{~ m m}\end{array}$ & $\begin{array}{c}\text { Material } \\
\text { No. }\end{array}$ & $\begin{array}{c}\text { Thickness } \\
\text { in } \mathbf{~ m m} \\
\end{array}$ & $\begin{array}{c}\text { Material } \\
\text { No. }\end{array}$ & $\begin{array}{c}\text { Thickness } \\
\text { in } \mathbf{~ m m} \\
\end{array}$ \\
\hline 1 & 16 & 0.3323 & 16 & 0.2018 & 16 & 0.2284 \\
\hline 2 & 6 & 0.4414 & 6 & 1.3296 & 6 & 1.0805 \\
\hline 3 & 2 & 0.3648 & 14 & 0.1192 & 9 & 0.5624 \\
\hline 4 & 11 & 0.4656 & 11 & 0.6961 & 12 & 0.1099 \\
\hline 5 & 9 & 0.4220 & 9 & 0.6254 & 9 & 0.6651 \\
\hline 6 & \multicolumn{2}{|c|}{ Ground plane } & \multicolumn{2}{|c|}{ Ground plane } & \multicolumn{2}{|c|}{ Ground plane } \\
\hline $\begin{array}{l}\text { Maximum } \\
\text { reflection } \\
\text { coefficient in } \\
\text { dB }\end{array}$ & \multicolumn{2}{|c|}{-15.7872} & \multicolumn{2}{|c|}{-18.7609} & \multicolumn{2}{|c|}{-17.0341} \\
\hline $\begin{array}{l}\text { Total thickness } \\
\text { in } \mathbf{~ m m}\end{array}$ & \multicolumn{2}{|c|}{2.0261} & \multicolumn{2}{|c|}{2.9722} & \multicolumn{2}{|c|}{2.6463} \\
\hline
\end{tabular}

Table 4. Comparative Statistical Analysis After 20 Trials For Model1

\begin{tabular}{|c|c|c|c|c|}
\hline Algorithm & Best & Worst & Mean & $\begin{array}{c}\text { Standard } \\
\text { deviation }\end{array}$ \\
\hline PSO & -9.7091 & -8.1827 & -9.0438 & 0.3933 \\
\hline FA & -9.8443 & -4.3626 & -7.9062 & 1.4860 \\
\hline ABC & -9.0952 & -8.0470 & -8.5155 & 0.2965 \\
\hline
\end{tabular}

Table 5. Parameters For Microwave Absorber Design For Oblique Incidence $\left(30^{\circ}\right)$ TM Polarization Optimized For Overall Reflection Coefficient Only (Model2) 


\begin{tabular}{|c|c|c|c|c|c|c|}
\hline \multirow[b]{2}{*}{ Layer } & \multicolumn{2}{|c|}{ PSO } & \multicolumn{2}{|c|}{ FA } & \multicolumn{2}{|c|}{$\mathrm{ABC}$} \\
\hline & $\begin{array}{l}\text { Material } \\
\text { No. }\end{array}$ & $\begin{array}{l}\text { Thickness } \\
\text { in } \mathbf{~ m m}\end{array}$ & $\begin{array}{l}\text { Material } \\
\text { No. }\end{array}$ & $\begin{array}{l}\text { Thickness } \\
\text { in } \mathbf{~ m m}\end{array}$ & $\begin{array}{c}\text { Material } \\
\text { No. }\end{array}$ & $\begin{array}{l}\text { Thickness } \\
\text { in } \mathbf{~ m m}\end{array}$ \\
\hline 1 & 16 & 0.1573 & 14 & 0.1635 & 16 & 0.1685 \\
\hline 2 & 6 & 1.7519 & 6 & 1.8124 & 6 & 1.8329 \\
\hline 3 & 16 & 0.4559 & 16 & 0.4153 & 16 & 0.5201 \\
\hline 4 & 5 & 1.1076 & 5 & 0.7171 & 7 & 0.1529 \\
\hline 5 & 4 & 1.4634 & 10 & 1.8524 & 11 & 1.2277 \\
\hline 6 & \multicolumn{2}{|c|}{ Ground plane } & \multicolumn{2}{|c|}{ Ground plane } & \multicolumn{2}{|c|}{ Ground plane } \\
\hline $\begin{array}{c}\text { Maximum } \\
\text { reflection } \\
\text { coefficient in } \\
\text { dB }\end{array}$ & \multicolumn{2}{|c|}{-23.0826} & \multicolumn{2}{|c|}{-21.5938} & \multicolumn{2}{|c|}{-20.8239} \\
\hline $\begin{array}{l}\text { Total thickness } \\
\text { in } \mathbf{~ m m}\end{array}$ & \multicolumn{2}{|c|}{4.9361} & \multicolumn{2}{|c|}{4.9606} & \multicolumn{2}{|c|}{3.902} \\
\hline & & & & & & \\
\hline
\end{tabular}

Table 6. Comparative statistical analysis after 20 trials for model 2

\begin{tabular}{|c|c|c|c|c|}
\hline Algorithm & Best & Worst & Mean & $\begin{array}{c}\text { Standard } \\
\text { deviation }\end{array}$ \\
\hline PSO & -23.0826 & -17.4886 & -20.1828 & 1.8365 \\
\hline FA & -21.5938 & -17.4248 & -18.6764 & 1.1049 \\
\hline ABC & -20.8239 & -16.9545 & -18.5162 & 1.1329 \\
\hline
\end{tabular}

Table 7. Parameters For Microwave Absorber Design For Oblique Incidence $\left(30^{\circ}\right)$ TE Polarization Optimized For Overall Reflection Coefficient And Total Thickness Of The Absorber (Model3) 
International Journal of Microwave Engineering (JMICRO) Vol.1, No.1, January 2016

\begin{tabular}{|c|c|c|c|c|c|c|}
\hline \multirow{2}{*}{ Layer } & \multicolumn{2}{|c|}{ PSO } & \multicolumn{2}{c|}{ FA } & \multicolumn{2}{c|}{ ABC } \\
\cline { 2 - 7 } & $\begin{array}{c}\text { Material } \\
\text { No. }\end{array}$ & $\begin{array}{c}\text { Thickness } \\
\text { in mm }\end{array}$ & $\begin{array}{c}\text { Material } \\
\text { No. }\end{array}$ & $\begin{array}{c}\text { Thickness } \\
\text { in mm }\end{array}$ & $\begin{array}{c}\text { Material } \\
\text { No. }\end{array}$ & $\begin{array}{c}\text { Thickness } \\
\text { in mm }\end{array}$ \\
\hline 1 & 16 & 0.3732 & 16 & 0.3742 & 16 & 0.3899 \\
\hline 2 & 8 & 0.1523 & 1 & 0.3992 & 7 & 0.4032 \\
\hline 3 & 7 & 0.2225 & 2 & 0.3902 & 2 & 0.4409 \\
\hline 4 & 2 & 0.4290 & 13 & 0.1006 & 15 & 0.3826 \\
\hline 5 & 15 & 0.4825 & 15 & 0.4063 & 16 & 0.1495 \\
\hline 6 & Ground plane & Ground plane & Ground plane \\
\hline $\begin{array}{c}\text { Maximum } \\
\text { reflection } \\
\text { coefficient in } \\
\text { dB }\end{array}$ & \multicolumn{2}{c}{-11.2147} & -11.0730 & -11.0220 & \\
\hline $\begin{array}{c}\text { Total } \\
\text { thickness in } \\
\text { mm }\end{array}$ & \multicolumn{2}{c}{1.6705} & & \multicolumn{2}{c}{1.766} \\
\hline
\end{tabular}

Table 8. Comparative Statistical Analysis After 20 Trials For Model3

\begin{tabular}{|c|c|c|c|c|}
\hline Algorithm & Best & Worst & Mean & $\begin{array}{c}\text { Standard } \\
\text { deviation }\end{array}$ \\
\hline PSO & -6.2362 & -3.9262 & -4.9741 & 0.5123 \\
\hline FA & -6.0614 & -2.9609 & -4.6205 & 0.6904 \\
\hline ABC & -5.7239 & -4.7002 & -5.1360 & 0.2896 \\
\hline
\end{tabular}

Table 9. Parameters For Microwave Absorber Design For Oblique Incidence $\left(30^{\circ}\right)$ TE Polarization Optimized For Overall Reflection Coefficient Only (Model4)

\begin{tabular}{|c|c|c|c|c|c|c|}
\hline \multirow{2}{*}{ Layer } & \multicolumn{2}{|c|}{ PSO } & \multicolumn{2}{c|}{ FA } & \multicolumn{2}{c|}{ ABC } \\
\cline { 2 - 7 } & $\begin{array}{c}\text { Material } \\
\text { No. }\end{array}$ & $\begin{array}{c}\text { Thickness } \\
\text { in mm }\end{array}$ & $\begin{array}{c}\text { Material } \\
\text { No. }\end{array}$ & $\begin{array}{c}\text { Thickness } \\
\text { in mm }\end{array}$ & $\begin{array}{c}\text { Material } \\
\text { No. }\end{array}$ & $\begin{array}{c}\text { Thickness } \\
\text { in mm }\end{array}$ \\
\hline 1 & 16 & 0.2243 & 16 & 0.2199 & 16 & 0.2156 \\
\hline 2 & 6 & 1.9998 & 6 & 1.8861 & 6 & 1.9705 \\
\hline 3 & 16 & 0.5908 & 14 & 0.4352 & 14 & 0.4966 \\
\hline 4 & 1 & 1.3214 & 5 & 1.1419 & 5 & 1.1380 \\
\hline 5 & 11 & 1.0558 & 10 & 0.8240 & 9 & 0.3961 \\
\hline 6 & \multicolumn{7}{|c|}{ Ground plane } & Ground plane & Ground plane \\
\hline $\begin{array}{c}\text { Maximum } \\
\text { reflection } \\
\text { coefficient in } \\
\text { dB }\end{array}$ & \multicolumn{7}{|c|}{-15.3363} & -14.9729 & \\
\hline
\end{tabular}


International Journal of Microwave Engineering (JMICRO) Vol.1, No.1, January 2016

\begin{tabular}{|c|l|l|l|}
\hline $\begin{array}{c}\text { Total thickness } \\
\text { in mm }\end{array}$ & 5.1920 & 4.5071 & 4.2168 \\
\hline
\end{tabular}

Table 10. Comparative statistical analysis after 20 trials for model4

\begin{tabular}{|c|c|c|c|c|}
\hline Algorithm & Best & Worst & Mean & $\begin{array}{c}\text { Standard } \\
\text { deviation }\end{array}$ \\
\hline PSO & -15.8569 & -13.2509 & -14.7254 & 0.7198 \\
\hline FA & -15.3363 & -12.8856 & -14.0259 & 0.7724 \\
\hline ABC & -14.9729 & -12.9493 & -13.8431 & 0.5397 \\
\hline
\end{tabular}

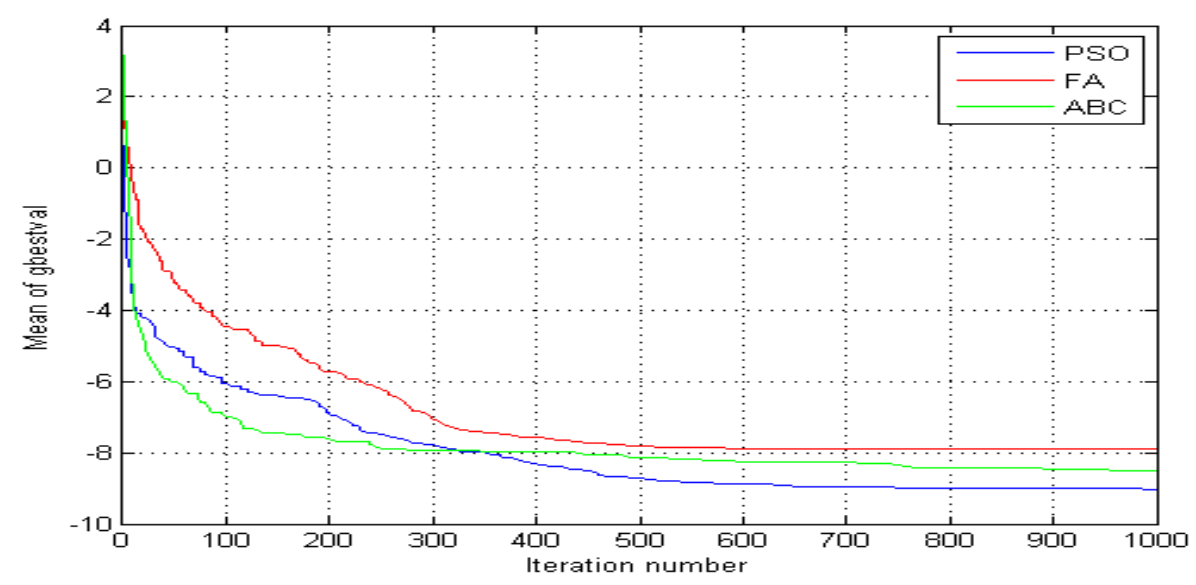

Figure 9.Mean of best fitness value versus iteration (Model 1)

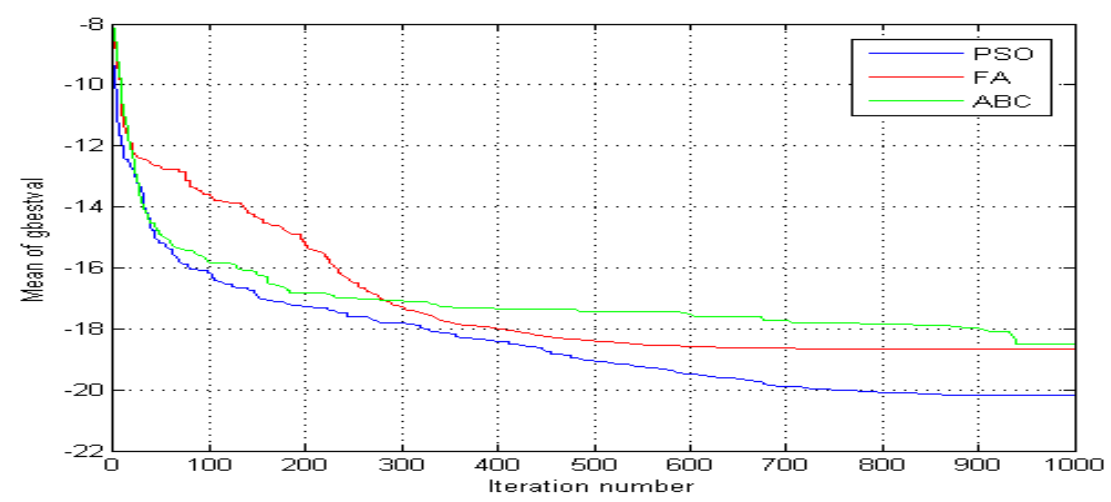

Figure 10. Mean of best fitness value versus iteration (Model 2) 


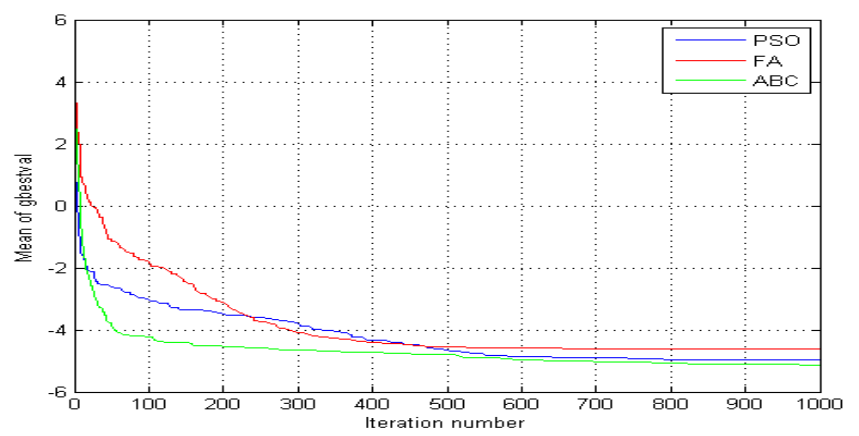

Figure 11. Mean of best fitness value versus iteration (Model 3)

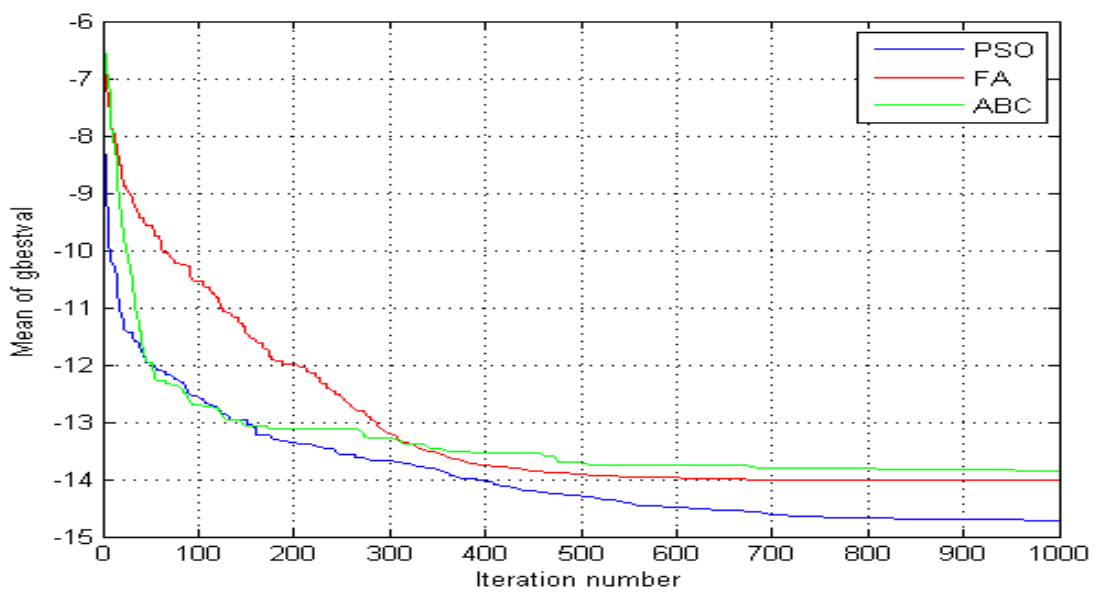

Figure 12. Mean of best fitness value versus iteration (Model 4)

\section{CONCLuSiOnS}

A comparative study of three very popular evolutionary algorithm such as particle swarm optimization (PSO), firefly algorithm (FA) and artificial bee colony optimization (ABC) has been presented in this paper for the optimum design of thin broadband multilayer microwave absorber for oblique incidence $\left(30^{\circ}\right)$ considering arbitrary polarization of the electromagnetic wave. The comparison of simulation results for different parameters and their statistical analysis between different algorithm have been demonstrate for every model which make our study more convenient for the design of the same. Moreover, it has also been emphasized that for normal incidence of electromagnetic wave both TE and TM yield the same magnitude of the reflection coefficient and set the reflection coefficient between the last layer of the multilayer structure and the PEC $\left(R_{N, N+1}\right)$ to +1 for TM polarization where as it set to -1 for TE polarization of the electromagnetic wave, which seems to be neglected in many papers handling the same problem.

\section{REFERENCES}

[1] Eric Michielssen, Jean-Michel Sajer, S. Ranjithan, and Raj Mittra, "Design of lightweight, broad-band microwave absorbers using genetic algorithms," IEEE Trans. on Microwave Theory and Techniques, Vol. 41, No. 6/7, 1024-1031, June/July 1993. 
[2] Weile, D., E. Michielssen, and D. Goldberg, "Genetic algorithm design of pareto optimal broadband microwave absorbers," IEEE Trans. on Electromagnetic Compatibility, Vol. 38, No. 3, 518-525, August 1996.

[3] Jorge Andrey da Silva Mac^edo, Marco Jos’e de Sousa, Victor Dmitriev, "Optimization of wide-band multilayer microwave absorbers for any angle of incidence and Arbitrary Polarization" 0-7803-93422/05/\$20.00 @ 2005 IEEE.

[4] S. Chamaani, S. A. Mirtaheri, M. Teshnehlab, M. A. Shoorehdeli and V. Seydi, "Modified multiobjective particle swarm optimization for electromagnetic absorber design" Progress In Electromagnetics Research, PIER 79, 353-366, 2008

[5] Chamaani, S., S. Mirtaheri, and M. Shooredeli, "Design of very thin wide band absorbers using modified local best particle swarm optimization," AEU-Int. J. Electron Commun, Vol. 62, 549-556, 2008.

[6] L. Jiang, J. Cui, L. Shi, X. Li, "Pareto optimal design of multilayer microwave absorbers for wideangle incidence using genetic algorithms", IET Microw. Antennas Propag., 2009, Vol. 3, Iss. 4, pp. $572-579$

[7] M. J. Asi and N. I. Dib, "Design of multilayer microwave broadband absorbers using central force optimization"Progress In Electromagnetics Research B, Vol. 26, 101-113, 2010.

[8] N. Dib, M. Asi, and A. Sabbah, "On the optimal design of multilayer microwave absorbers "Progress In Electromagnetics Research C, Vol. 13, 171-185, 2010.

[9] Chew, W. C., Waves and Fields in Inhomogeneous Media, IEEE Press, New York, 1995.

[10] L. Jiang J. Cui L. Shi X. Li, "Pareto optimal design of multilayer microwave absorbers for wide-angle incidence using genetic algorithms", IET Microw. Antennas Propag., 2009, Vol. 3, Iss. 4, pp. 572-579

[11]Goudos, S., "Design of microwave broadband absorbers using a self-adaptive differential evolution algorithm," Int. J. RF and Microwave CAE, Vol. 19, pp.364-372, May 2009.

[12] Michielssen, E., J. Sajer, S. Ranjithan, and R. Mittra, "Design of lightweight, broad-band microwave absorbers using genetic algorithms," IEEE Trans. on Microwave Theory and Techniques, Vol. 41, No. 6/7, pp.1024-1031, June/July 1993.

[13] J. Kennedy and R. C. Eberhart, "Particle swarm optimization," in Proc.IEEE Int. Conf. Neural Networks,Perth,Australia 1995, pp. 1942-1948.

[14] W. T. Li, X. W. Shi and Y. Q. Hei, "An Improved Particle Swarm Optimization Algorithm for Pattern Synthesis of Phased Arrays," Progress In Electromagnetics Research, PIER 82, pp.319-332, 2008.

[15]J. Robinson, and Y. Rahmat-Samii, "Particle swarm optimization in electromagnetics," IEEE Transactions on Antennas and Propagation, Vol. 52, No. 2, pp.397-407, February 2004.

[16] N. Jin and Y. Rahmat-Samii, "Advances in particle swarm optimization for antenna designs: Realnumber, binary, single- objective and multiobjective implementations," IEEE Trans. Antennas Propag., Vol. 55, no. 3, pp.556-567, March 2007.

[17] T. B. Chen, Y. L. Dong, Y. C. Jiao, and F. S. Zhang, "Synthesis of circular antenna array using crossed particle swarm optimization algorithm," Journal of Electromagn. Waves and Appl., Vol. 20, No. 13, pp.1785-1795, 2006.

[18] D. W. Boeringer,and D. H.Werner, "Particle swarm optimization versus genetic algorithms for phased array synthesis," IEEE Transactions on Antennas and Propagation, Vol. 52, No. 3, pp.771-779, 2004.

[19] Bansal, J. C., P. K. Singh, MukeshSaraswat, AbhishekVerma, Shimpi Singh Jadon, and Ajith Abraham. "Inertia weight strategies in particle swarm optimization." In Nature and Biologically Inspired Computing (NaBIC), 2011 Third World Congress on,Salamanca, Spain, pp. 633-640. IEEE, 2011.

[20] Liang, J. J., and PonnuthuraiNagaratnamSuganthan. "Dynamic multi-swarm particle swarm optimizer." In Swarm Intelligence Symposium, 2005. SIS 2005. Proceedings, Pasadena, California 2005 IEEE, pp. 124-129. IEEE, 2005.

[21] K. R. Mahmoud, M. I. Eladawy, R. Bansal, S. H. Zainud-Deen, and S. M. M. Ibrahem, "Analysis of uniform circular arrays for adaptive beamforming applications using particle swarm optimization algorithm," International Journal of RF and Microwave Computer-Aided Engineering, vol. 18, no. 1, pp. 42-52, January 2008. 
[22] Yang, X.S.: Firefly algorithms for multimodal optimization, in Stochastic Algorithms: Foundations and Applications, Lecture Notes in Computer Sciences, vol. 5792, Springer, Berlin, 2009, 169-178.

[23] Łukasik, S.; Z ak, S.: Firefly algorithm for continuous constrained optimization tasks, in Computational Collective Intelligence. Semantic Web, Social Networks and Multiagent Systems, Lecture Notes in Computer Science, vol. 5796, Springer, Berlin, 2009, 97-106.

[24] Yang, X.S.: Engineering Optimization: An Introduction with Metaheuristic Applications, John Wiley \& Sons, New Jersey, 2010.

[25] Karaboga, D.; Basturk, B.: Artificial bee colony (ABC) optimization algorithm for solving constrained optimization problems, InLNCS: Advances in Soft Computing: Foundations of Fuzzy Logicand Soft Computing, Springer-Verlag, 2007, vol. 4529, 789-798.

[26] Karaboga, D.; Basturk, B.: A powerful and efficient algorithm for numerical function optimization: artificial bee colony (ABC) algorithm.J. Global Optim., 39 (3) (2007), 459-471.

\section{AUTHORS}

JyotirmayTewary received his Bachelor of Engineering (B.E) degree in Electronics \& Telecommunication Engineering from Amravati University Maharashtra, India and M.Tech from National Institute of Technology Durgapur, India. Presently he is working towards his $\mathrm{PhD}$ in Electronics \& Communication

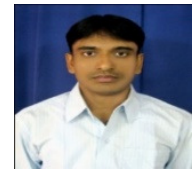
Engineering from National Institute of Technology Durgapur, India. Initially he started his career as engineer quality control at Sparrow Electronics Limited Verna Goa, later on he joined Aryabhatta Institute of Engineering \& Management Durgapur, India as a Lecturer in the Department of Electronics \& communication Engineering and presently he is working as Assistant Professor in the Department of Electronics \& communication Engineering at Bengal college of Engineering \& Technology Durgapur, India. His current research interest includes Microwave Engineering, EMI/EMC, Optimization, Computational Electromagnetic and Evolutionary Algorithm.

G.K.Mahanti was born in West Bengal, India. He obtained his B.E. in Electronics \& Communication Engg. from NIT, Durgapur, India, M.E. in Electronics System and Communication from NIT, Rourkela, India and Ph.D(Engg.) from IIT, Kharagpur, India. He has more than 20 years of teaching and research experience. Presently he is working as a Professor, department of Electronics and

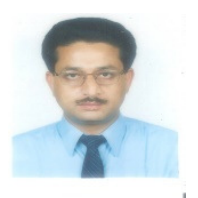
Communication Engineering, National Institute of Technology, Durgapur, India. He is a senior member of IEEE, USA. He has produced seven Ph.D students so far. He was session chair of many conferences. He was former Head of the department of ECE, NIT, Durgapur. He has published approximately 80 papers in journals and in national and international conferences. $\mathrm{He}$ was the reviewer of many international journals like Electronics Letter, IEEE Antennas and Wireless Propagation Letter, Progress in Electromagnetics Research, IET Microwave, Antenna and Propagation and many conferences. He was also the program committee member of many national and international conferences. His biography is listed in Marqui'sWho is Who in the world.His research area is Array antenna synthesis, Evolutionary Algorithms \&Electromagnetics.

KajlaBasu completed her M.Sc and Ph.D degree in Mathematics from IIT,Kharagpur.She has published 40 papers in international \& national journals and conference proceedings. She is presently a professor in the department of Mathematics,NIT, Durgapur. She was also former head of the department of

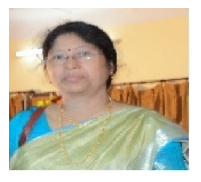
Mathematics.Her research area is operation research and statistical analysis. 